\title{
Simple Excision of Nasal Polyps
}

National Cancer Institute

\section{Source}

National Cancer Institute. Simple Excision of Nasal Polyps. NCI Thesaurus. Code C51890.

A surgical procedure in which uncomplicated polyps are removed from the nose. 